\title{
A Rare and Important Cause of Winging of the Scapula
}

\section{Witney-Lagen CJ*, Newman JB, Wragg MR, Dawson R and Williams HR}

Orthopaedic Department, York District Hospital, Wiggington Road, York, Yorkshire, YO31 8HE, UK

\section{Case Report}

A 47 year old lady presented to the Orthopaedic out patient clinic following a referral from her General Practitioner. Since 2001 she had suffered from right-sided shoulder pain. In addition she reported a feeling of instability in the shoulder when doing manual activities, especially in over-head work. On questioning she reported occasional hand paraesthesia. This affected all of the fingers and thumb equally, rather than being confined to a particular nerve region or dermatome. There was no history of trauma.

Her past medical history included a right total mastectomy for adeno-carcinoma of the breast in 2004. The tumour was completely excised and after taking tamoxifen for two years she was followed up for five years before being discharged. Interestingly, she had also been diagnosed with Hodgkin's Lymphoma at the age of twenty. This was successfully treated with radiotherapy. She was not taking any medications and was otherwise well.

Clinical examination revealed an elevated abducted scapula with winging. There was a full range of movement of the shoulder with pain at approximately 90 degrees of forward flexion and also at 90 degrees of abduction. Instability tests were negative. There was no demonstrable abnormal neurology.

The initial impression was that of a brachial neuritis, possibly secondary to previous radiotherapy. However her radiotherapy was 27 years in the past and she had not developed symptoms until 2001. She was referred for physiotherapy and a MRI scan was requested.

The MRI pictures are shown in Figure 1 with axial and coronal $\mathrm{T} 1$ and T2 weighted images. These demonstrate a 10/3/5 centimetre mass arising from the subscapularis muscle. The mass enhances in homogeneously and has a mass effect on the scapula, thinning the adjacent cortex. This scan was reported as strongly suggestive of a soft tissue sarcoma.

An urgent referral was made to the local sarcoma service for tissue diagnosis to aid further management. Core biopsy of the mass revealed grade three pleomorphic sarcoma. Further opinion was sought from the professor of Surgical Oncology and the patient went on to have a right forequarter amputation. At operation the tumour did not breech the serratus anterior muscle. Pathological examination of the specimen demonstrated complete excision of the tumour. At one year followup the staging proved negative for metastatic spread and also for local recurrence.

\section{Discussion}

Our patient presented with shoulder pain, instability and hand paraesthesia. The only objective clinical finding was winging of the scapula. Common causes of winging include loss of function of the serratus anterior muscle with long thoracic nerve damage, loss of function of the trapezius muscle (for example in spinal accessory nerve damage), brachial plexus injuries and muscular dystrophy. To our knowledge there are no other reported cases of a soft tissue sarcoma presenting with winging of the scapula.

Literature searches have revealed a number of reports of subscapular masses with varied clinical presentations. The most commonly reported subscapular masses are elastofibromas. To our knowledge our patient is the first subscapular mass histologically diagnosed as a soft tissue sarcoma. Fibla et al. [1] report elastofibromas as rare benign soft tissue tumours that are almost always located at the inferior pole of the scapula, deep to the serratus anterior muscle. They reported a case of bilateral subscapular masses in a 55-year-old female who presented with chronic pain of the shoulder. Similarly Erdas et al. [2] reported a case of a 51-year-old female with an elastofibroma presenting with shoulder pain, a clicking sensation and an infrascapular swelling. Majeski [3] also reported a case of bilateral elastofibroma presenting as masses protruding from beneath the inferior angle of the scapula in a 69-year-old male when he adducted and elevated his arms. Like our patient, all of these patients presented with shoulder pain. However, our patient did not have clicking or a visible mass. Logically an altered range of scapulothoracic movement could be expected if the mass was large or if it damaged adjacent nerves.

Interestingly there were a number of case reports in the literature where patients have developed sarcomas following irradiation therapy. The largest study by Pitcher et al. [4] reports 38 patients developing
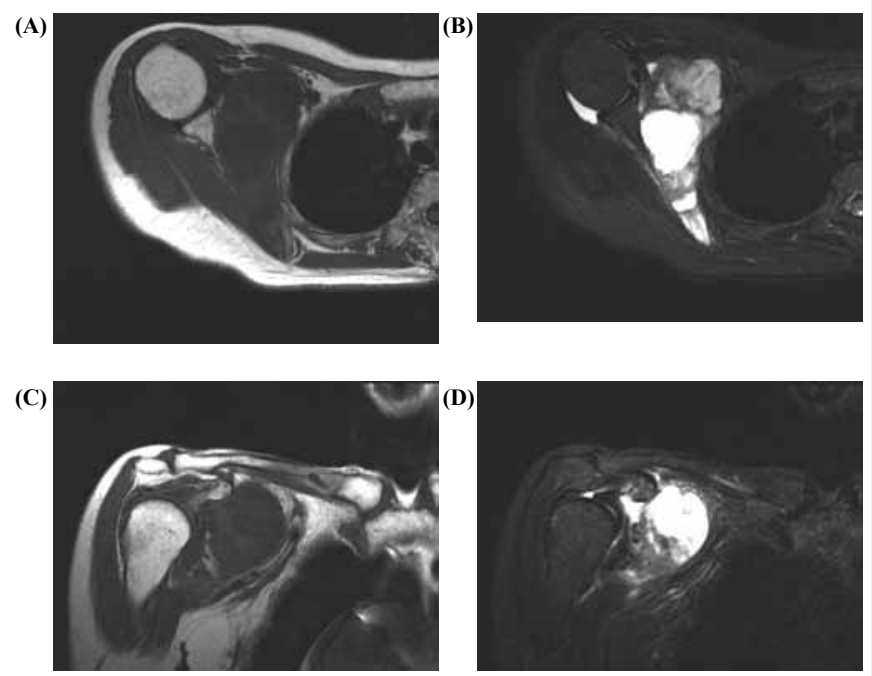

Figure 1: MRI of the right shoulder

A) Axial T1 image

B) Axial T2 image

C) Coronal T1 image

D) Coronal T2 image

${ }^{*}$ Corresponding author: Witney-Lagen CJ, Orthopaedic Department, York Distric Hospital, Wiggington Road, York, Yorkshire, YO31 8HE, UK, Tel: 01904 631313; E-mail: carolinejws@gmail.com

Received April 18, 2012; Accepted June 16, 2012; Published June 26, 2012

Citation: Witney-Lagen CJ, Newman JB, Wragg MR, Dawson R, Williams HR (2012) A Rare and Important Cause of Winging of the Scapula. J Clin Case Rep 2:159. doi:10.4172/2165-7920.1000159

Copyright: (C) 2012 Witney-Lagen CJ, et al. This is an open-access article distributed under the terms of the Creative Commons Attribution License, which permits unrestricted use, distribution, and reproduction in any medium, provided the original author and source are credited. 
Citation: Witney-Lagen CJ, Newman JB, Wragg MR, Dawson R, Williams HR (2012) A Rare and Important Cause of Winging of the Scapula. J Clin Case Rep 2:159. doi:10.4172/2165-7920.1000159

sarcomas post radiotherapy. In this study the most common causes for radiotherapy were breast carcinoma and lymphoma. The median time from radiotherapy to development of sarcoma was 11 years. Our patient had received radiotherapy for lymphoma twenty-seven years prior to presentation in the Orthopaedic clinic.

In summary, soft tissue sarcomas in the subscapular region are extremely rare. In addition to pain, they can present with winging of the scapula. Due to the aggressive nature of sarcoma it is important to differentiate them from the more common and benign subscapular elastofibroma. Accurate diagnosis can be achieved with biopsy. Previous radiotherapy may well be a risk factor for development of subscapular sarcoma. We believe soft tissue sarcoma should be considered as a diagnosis in any patient presenting with shoulder pain along with instability or winging and a subscapular mass.

\section{References}

1. Fibla J, Molins L, Marco V, Pérez J, Vidal G (2007) Bilateral elastofibroma dorsi. Joint Bone Spine 74: 194-196.

2. Erdas E, Licheri S, Pinna G, Gerosa C, Ragazzo G (2006) Elastofibroma dorsi case report and review of the literature. G Chir 27: 372-376.

3. Majeski J (2008) Elastofibroma: a subscapular mass. Am J Surg 196: 93-94.

4. Pitcher ME, Davidson TI, Fisher C, Thomas JM (1994) Post irradiation sarcoma of soft tissue and bone. Eur J Surg Oncol 20: 53-56. 